\title{
Intra-host dynamics of mixed species malaria parasite infections in mice and mosquitoes
}

\author{
Jianxia Tang ${ }^{1 \dagger}$, Megumi Inoue ${ }^{1 \dagger}$, Toshihiko Sunahara ${ }^{2}$, Moe Kanda ${ }^{1}$, Osamu Kaneko ${ }^{1}$, Richard Culleton ${ }^{1 *}$ \\ From Parasite to Prevention: Advances in the understanding of malaria \\ Edinburgh, UK. 20-22 October 2010
}

\section{Background}

The distributions of human malaria parasite species overlap in most regions of the world where malaria is present, and co-infections involving two or more malaria parasites are common. Currently, very little is known about the consequences of any interactions that may occur between species during co-infection for disease severity and parasite transmission success. However, current anti-malarial interventions such as vector control and drug interventions and the future application of vaccines will and do have disproportionate effects on some species compared to others; with the ultimate consequence of reducing the number of species in circulation in any one area. We believe that such a situation warrants a clearer understanding of how the interactions between species affect malaria disease and transmission dynamics.

\section{Methods}

As controlled competition experiments using human malaria parasites are currently practically impossible, we assessed the consequences of mixed-species infections on parasite fitness, disease severity and transmission success using the rodent malaria parasite species Plasmodium chabaudi (strains AS and CB), P. yoelii yoelii (CU) and P. vinckei lentum (DS). We compared the fitness of individual species within co-infections and in single species infections in mice. We also assessed the disease severity of single versus mixed infections in mice by measuring mortality rates, anaemia and weight loss.
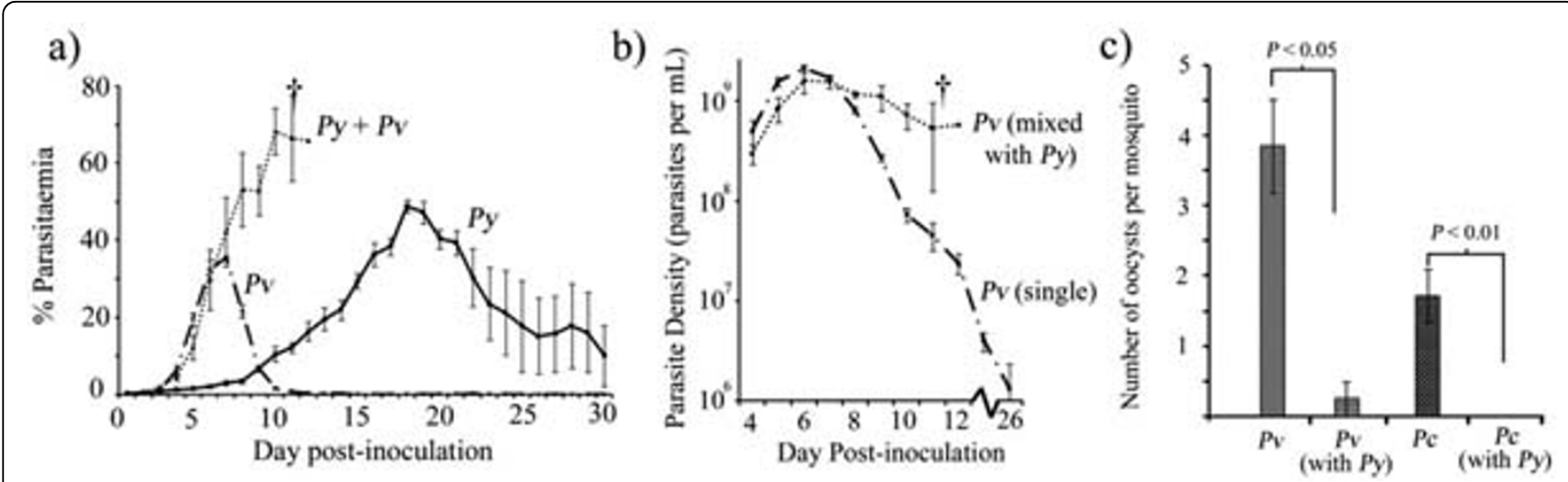

Figure 1 (a) Parasitaemia of mixed and single infections of P.yoelii and P. vinckei, in the mixed infection group, all mice died by day 12 postinoculation. (b) Parasite density of $P$. vinckei in a mixed infection with P.yoelii, and in a single infection. (c) mean oocyst production per mosquito of $P$.vinckei and $P$. chabaudi in mixed infections with $P$. yoelii, and in a single infections. Data are means of five mice per group; error bars represent one standard error above and below the mean. $P v=P$. vinckei, $P C=P$. chabaudi, $P y=P$.yoelii. $\dagger=$ death.

\footnotetext{
† Contributed equally

'Department of Protozoology, Institute of Tropical Medicine (NEKKEN),

Nagasaki University, 1-12-4 Sakamoto Nagasaki 852-852, Japan
}

Full list of author information is available at the end of the article

(c) 2010 Culleton et al; licensee BioMed Central Ltd. This is an open access article distributed under the terms of the Creative Commons
Attribution License (http://creativecommons.org/licenses/by/2.0), which permits unrestricted use, distribution, and reproduction in :HOWed Central Attribution License (http://creativecommons.org/licenses/by/2 
Finally, we compared the transmission success of parasites in single or mixed species infections by quantifying oocyst development in Anopheles stephensi mosquitoes.

\section{Results}

We found that co-infections of $P$. yoelii with either $P$. vinckei or $P$. chabaudi led to a dramatic increase in infection virulence, with $100 \%$ mortality observed in mixed species infections, compared to no mortality for $P$. yoelii and $P$. vinckei single infections, and $40 \%$ mortality for $P$. chabaudi single infections. The increased mortality in the mixed infections was associated with an inability to clear parasitaemia (Figure 1a), with the non$P$. yoelii parasite species persisting at higher parasite densities than in single infections (Figure 1b). P. yoelii growth was suppressed in all mixed infections compared to single infections. Transmissibility of $P$. vinckei and P. chabaudi to mosquitoes was also dramatically reduced in the presence of P. yoelii in co-infections compared to single infections (Figure 1c).

\section{Discussion}

The increased virulence of co-infections containing $P$. yoelii (reticulocyte restricted) and P. chabaudi or P. vinckei (predominantly normocyte restricted) may be consequences of parasite cell tropism and/or immune modulation of the host. We explain the reduction in transmission success of species in co-infections in terms of inter-species gamete incompatibility.

\section{Author details}

'Department of Protozoology, Institute of Tropical Medicine (NEKKEN),

Nagasaki University, 1-12-4 Sakamoto Nagasaki 852-852, Japan. ${ }^{2}$ Department of International Health, Institute of Tropical Medicine (NEKKEN), Nagasaki, 112-4 Sakamoto Nagasaki 852-852, Japan.

Published: 20 October 2010

doi:10.1186/1475-2875-9-S2-031

Cite this article as: Tang et al.: Intra-host dynamics of mixed species malaria parasite infections in mice and mosquitoes. Malaria Journal 2010 9(Suppl 2):031.
Submit your next manuscript to BioMed Central and take full advantage of:

- Convenient online submission

- Thorough peer review

- No space constraints or color figure charges

- Immediate publication on acceptance

- Inclusion in PubMed, CAS, Scopus and Google Scholar

- Research which is freely available for redistribution

Submit your manuscript at www.biomedcentral.com/submit 